\title{
Histopathological and immunohistochemical parameters of breast cancer cases analyzed in a reference laboratory
}

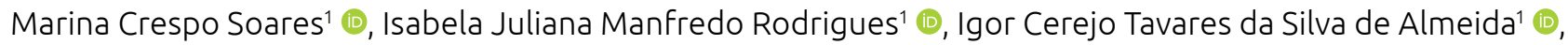

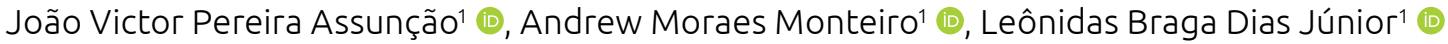

\section{ABSTRACT}

Objective: To determine the histopathological and immunohistochemical parameters of breast cancer cases treated in Belém, state of Pará, Brazil. Method: This is a cross-sectional, retrospective and observational study in which samples from 278 patients were analyzed. In the histopathological analysis were considered, among other factors, the differentiation and histopathological classification of the tumor, based on the WHO classification. As for immunohistochemistry, the presence and intensity of expression of the cell proliferation antigen Ki-67, gene product of HER2, and estrogen and progesterone receptors were evaluated. Then, the tumors were classified into luminal A, luminal B, luminal hybrid, HER2 group, and basal-like. Results: The most common histological subtypes were invasive carcinoma of no special type (88.7\%), carcinoma in situ (5.5\%), and invasive mucinous carcinoma (2.9\%). The most common immunohistochemical subtypes were luminal A (26.1\%), basal-like (23.6\%), and luminal B (23.2\%). We also found a statistically significant inversely proportional relationship $(p<0.01)$ of hormone receptor expression with nuclear grade. Conclusion: The results show the importance of immunohistochemical analysis for staging, as well as for the therapeutic decision of each patient. However, further studies with a larger sample must be performed for more effective analysis of the general population.

KEYWORDS: breast cancer; immunohistochemistry; pathology.

\section{INTRODUCTION}

Breast cancer is a heterogeneous disease composed of multiple subgroups associated with distinct biological and histological characteristics, with different forms of clinical manifestation and patterns of response to current therapies. Histologically, invasive tumors are classified as invasive carcinoma of no special type (identified in medical practice as invasive ductal carcinoma - IDC), which corresponds to $70 \%$ of cases and is defined as a breast invasive epithelial neoplasm that does not meet the criteria for any special type, constituting a very heterogeneous group of tumors; and as the so-called histological special types, which are more homogeneous, with stricter diagnostic criteria, of which the invasive lobular carcinoma (ILC) is the most prevalent ${ }^{1}$. Histopathological parameters are traditionally used to evaluate tumor evolution by the Brazilian Society of Pathology (Sociedade Brasileira de Patologia).

Thus, the analysis of lesion size, axillary lymph node status, nuclear grade, and histological subtype are the basic aspects for defining primary prognostic factors. Histopathological characteristics of the lesion demonstrate different types of biological behavior of breast tumors ${ }^{2}$.

However, the histological classification of breast cancer has weaknesses. In addition to the subjectivity of the diagnostic criteria, when applying such classification, about $85 \%$ of the cases end up belonging to the two main categories of IDC or ILC. Therefore, the system fails to group tumors with a broad biological spectrum and clinical behavior in the same categories, making histologic grading and the immunohistochemical evaluation of estrogen receptor (ER), progesterone receptor (PR), HER2, and the Ki-67 proliferation index to play a key role in increasing the discriminatory value among the different cases of breast carcinoma ${ }^{3}$.

The presence of hormone receptors (HR) is associated with a more favorable prognosis. Therefore, patients with PR-positive tumors have longer disease-free survival and longer survival. Similarly, ER-positive tumors are associated with increased disease-free survival and also with a higher probability of response

'Department of Medicine, Universidade do Estado do Pará - Belém (PA), Brazil.

*Corresponding author: cvuepa@gmail.com

Conflict of interest: nothing to declare.

Received on: 11/12/2019. Accepted on: 12/30/2019. 
to hormone therapy. Conversely, patients with negativity for both receptors (ER and PR) showed worse prognosis than those with negativity for only one of the receptors 4 .

Another important tumor marker is the HER2 proto-oncogene, which is responsible for the production of a protein that transmits signals for the growth of epithelial cells, whose expression is often increased in breast cancer. HER2 overexpression results in a more aggressive clinical behavior of the tumor, and the analysis of the marker status is an important factor in detecting types of cancer with a worse prognosis ${ }^{5,6}$.

Tumors with high rates of cell proliferation are predominantly those with a high degree of malignancy. Thus, the evaluation of the mitotic activity is of paramount importance for assessing breast cancer. To that end, the cell proliferation index Ki-67 is used, a monoclonal antibody that detects a nuclear antigen, expressing cells entering the cell cycle and measuring the fraction of cell growth, thus enabling to detect tumors of a worse prognosis ${ }^{5}$.

\section{METHOD}

\section{Ethical aspects}

Patients of the present research were studied according to the precepts of the Declaration of Helsinki and the Nuremberg Code, respecting the Ethical Standards for Research Involving Human Beings (Resolution No. 466/12), of the National Health Council. The investigation started after the submission and approval of the project by the Research Ethics Committee of Universidade do Estado do Pará and was authorized by the director in charge of the Paulo C. Azevedo Laboratory (Laboratório Paulo C. Azevedo) and the advisor responsible for the research.

\section{Type of study, study population, and research site}

This is a cross-sectional, retrospective, and observational study conducted at the Paulo C. Azevedo Laboratory, from March to June 2017. We evaluated medical reports of the histopathological and immunohistochemical examinations of breast tumors performed in the laboratory from January 2016 to January 2017. A sample of 278 patients was considered, whose size was calculated based on a universe of 1,000 patients.

In order to define this sample size, a formula was used to calculate samples with a universe of less than 100,000, according to Equation 1:

$$
\mathrm{N}=\mathrm{d}^{2} \text {.p.q.U } / \mathrm{e}^{2}(\mathrm{U}-1)+\mathrm{d}^{2} \cdot \mathrm{p} \cdot \mathrm{q}
$$

where the universe $(\mathrm{U})$ of $y$, success rate of $50 \%$, failure rate of $50 \%$, standard deviation (d) of 2, and margin of error of $5 \%$ were adopted.

\section{Inclusion and exclusion criteria}

The sample included female patients over 18 years of age, whose medical reports of both histopathological and immunohistochemical examinations were stored in the archives of the Paulo C. Azevedo Laboratory, and who agreed to participate in the research by signing of the Informed Consent Form. All patients who presented only one of the required tests available and those who did not accept to participate in the study were excluded.

In the investigation protocol, the following data were collected: age, variables related to histopathological examination, and variables related to immunohistochemical examination.

Regarding histopathological aspects, the following were analyzed: tumor size; histologic/nuclear grade (differentiation grade); lymph nodes involvement and angiovascular invasion; presence of peritumoral inflammation; appropriate surgical margins; and histopathological classification of the tumor (IDC and ILC). As for immunohistochemical parameters, the following were evaluated: presence and intensity of expression of cell proliferation antigen (Ki-67); product of HER2 oncogene; and intensity of expression and presence of ER and PR (\% percentage / + score).

After this evaluation, tumors were classified as: luminal A (ER+ and/or PR+ HER2 - and KI-67<14\%); luminal B (ER+ and/ or PR+ HER2 - and KI-67 14\%); luminal hybrid (ER+ and/or PR+ HER2+); HER2 group (ER-, PR- HER2+); and basal-like (triplenegative cancer ER-, PR- and HER2-).

Tumor size was classified into four types, according to the TNM classification updated by the American Joint Committee on Cancer?:

- T1: tumor size less than or equal to $2 \mathrm{~cm}$ in diameter;

- T2: tumor size greater than $2 \mathrm{~cm}$, but less than or equal to $5 \mathrm{~cm}$ in its largest dimension;

- T3: tumor size greater than $5 \mathrm{~cm}$ in its largest dimension;

- T4: tumor of any size with extension to the chest wall or skin.

For the histological classification of invasive breast carcinoma, the World Health Organization (WHO) ${ }^{8}$ proposal was considered, according to Table 1.

\section{Data analysis}

Data were structured in the Microsoft Office Excel 2007 program and analyzed through the IBM Statistical Package for the Social Sciences (SPSS) program, software version 17.0. Descriptive analysis of the number of cases of breast cancer was performed as well as that of absolute and relative frequencies of each subtype of immunohistochemical and histopathological classification. Descriptive statistics of the age of patients affected by cancer were performed considering mean, standard deviation, median, and minimum and maximum values, in addition to the representation of this variable by classification according to menopausal status (cut-off point $=50$ years of age). 
Variables related to immunohistochemical analysis (ER, PR, product of HER2 oncogene, and cell proliferation antigen Ki-67) were cross-checked with the nuclear grade variable in order to verify correlations between them through Spearman's Correlation Coefficient, for ordinal variables, and Pearson's Correlation Coefficient, for scale variables.

Such immunohistochemical variables were also cross-checked with the presence of vascular invasion through the Mann-Whitney $\mathrm{U}$ test. The $\mathrm{p}<0.05$ value was considered in all tests with the cutoff point for statistical significance.

\section{DISCUSSION}

Of the 278 cases of breast cancer analyzed at the laboratory in 2016, 26.1\% were of the luminal A subtype; $23.6 \%$, basal-like or triple-negative; and 23.2\%, luminal B, as observed in Table 2. The results differ from those found by Cintra et al. ${ }^{5}$, in whose study $41.8 \%$ of cases were classified as luminal B. However, the percentage of triple-negative subtypes was $24.2 \%$, similar to that of the present study. Pérez-Rodríguez ${ }^{9}$, in a study with 1,380 Mexican women, achieved similar results: luminal A was the most prevalent subtype, though with the most expressive percentage, of $65 \%$, followed by the triple-negative (14\%), and luminal B (12\%). Mendoza del Solar et al. ${ }^{10}$ found frequency of the triple-negative

Table 1. Histological classification of invasive breast carcinoma.

\section{Histological types}

Invasive carcinoma of no special type

Invasive lobular carcinoma

Tubular carcinoma

Cribiform carcinoma

Carcinoma with medullary features

Metaplastic carcinoma

Carcinoma with apocrine differentiation

Adenoid cystic carcinoma

Mucoepidermoid carcinoma

Polymorphous adenocarcinoma

Mucinous carcinoma and signet ring cell carcinoma

Carcinoma with neuroendocrine features

Invasive papillary carcinoma

Invasive micropapillary carcinoma

Secretory carcinoma

Oncocytic carcinoma

Sebaceous carcinoma

Lipid-rich carcinoma

Glycogen-rich clear cell carcinoma

Acinar cell carcinoma

Source: $\mathrm{WHO}^{8}$ subtype in $30 \%$ of their sample, a number in line with our data. The triple-negative subtype is associated with more aggressiveness and worse survival ${ }^{10}$.

It is worth highlighting a key point in the research conducted by Pérez-Rodríguez": the luminal B subtype was classified according to the positivity of ER, PR, and HER2, which represents the luminal hybrid subtype of our study. This fact may explain the most expressive percentage of the luminal A subtype, since we considered cases with positivity for ER and PR in this subtype, and disregarded the percentage and the expression of the Ki-67 marker, which are generally used to distinguish luminal A and luminal B subtypes ${ }^{11}$.

The fourth most frequent subtype was the luminal hybrid (13.8\%) (ER+ and/or PR+ HER2+), a subtype poorly considered in similar research. The HER2+ subtype represented $10.1 \%$ of the cases analyzed in the period, a slightly higher value than the $8.92 \%$ perceived by Cherbal et al. ${ }^{12}$ Southeast and South regions, with a higher percentage of European ancestry and higher socioeconomic status, tend to have a higher percentage of luminal tumors. The Northern Region presented more aggressive subtypes (HER2+ and triple-negative), whereas in the Midwest cases of triple-positive carcinomas prevailed. The Northeast, a region with a high percentage of African ancestry, presented intermediate frequency ${ }^{13}$. This observation by Carvalho et al. ${ }^{13}$ may partly explain why, in the present study, lower percentages of luminal carcinomas and higher percentages

Table 2. Prevalence of breast cancer in a laboratory at Belém (PA), Brazil, in 2016, according to histopathological and immunohistochemical classifications.

\begin{tabular}{|l|c|c|}
\multirow{2}{*}{ Tumor subtypes } & \multicolumn{2}{|c}{ Frequency } \\
\cline { 2 - 3 } & N & $\%$
\end{tabular}

Histopathological subtypes

\begin{tabular}{l|c|c}
\hline Squamous cell carcinoma & 2 & 0.7 \\
\hline Carcinoma in situ & 15 & 5.5 \\
\hline Signet ring cell carcinoma & 1 & 0.4 \\
\hline Invasive carcinoma of no special type & 244 & 88.7 \\
\hline Invasive lobular carcinoma & 3 & 1.1 \\
\hline Invasive mucinous carcinoma & 8 & 2.9 \\
\hline Invasive papillary carcinoma & 2 & 0.7 \\
\hline
\end{tabular}

Molecular subtypes

\begin{tabular}{l|c|c}
\hline Luminal A & 72 & 26.1 \\
\hline Luminal B & 64 & 23.2 \\
\hline Luminal hybrid & 38 & 13.8 \\
\hline HER2 & 28 & 10.1 \\
\hline Basal-like & 65 & 23.6 \\
\hline Unspecified & 9 & 3.2 \\
\hline
\end{tabular}


of triple-negative carcinomas were found when compared with those in the global literature.

Sánchez-Muñoz et al. ${ }^{14}$, in a study with Spanish women, found a higher prevalence of luminal B subtype (51\%), followed by luminal A (19\%) and basal-like (5\%) subtypes. Fourati et al. ${ }^{15}$ identified a higher prevalence of luminal A (50.7\%), followed by triple-negative (22.5\%), and luminal B (13.4\%) tumor subtypes. These variations are due to differences between the analyzed populations and also the use of different classification parameters, in addition to the immunohistochemistry itself ${ }^{16}$.

The mean age at diagnosis was 53 years $( \pm 13.1)$, an age very similar to that surveyed by Pérez-Rodríguez ${ }^{9}$, which was 53.3 years, and slightly below the mean of 57.5 years observed by Meattini et al. ${ }^{17}$ However, the mean age observed by our study is slightly above that obtained by Cherbal et al. ${ }^{12}$ These differences may occur due to the heterogeneous variety of women analyzed in these studies.

Regarding the histological classification of breast cancer cases, the most frequent type found in the present study was invasive carcinoma of no special type (88.7\%), followed by carcinoma in situ (5.5\%), and invasive mucinous carcinoma (2.9\%). The frequency of invasive carcinomas of no special type in this study was higher than that identified by Caldarella et al. ${ }^{18}$, of $58.5 \%$. Meattini et al. ${ }^{17}$ found IDC as the most common histological subtype (64\%). Considering the new classification of invasive breast carcinomas according to the $\mathrm{WHO}^{8}$, this subtype is included in the group of invasive carcinoma of no special type. The other histological types found were: ILC (1.4\%), invasive papillary carcinoma $(0.7 \%)$, and squamous cell carcinoma $(0.7 \%)$. These data partly differ from the literature, especially when considering the low prevalence of ILC, which is generally responsible for $15 \%$ of breast cancer cases ${ }^{8}$.

In a study conducted in Brazil, Smaniotto et al. ${ }^{19}$ identified $70.49 \%$ of patients ( $\mathrm{n}=86)$ with the IDC type. The second most frequent lesion was ILC, in $9.84 \%$ of cases ( $n=12)$. Furthermore, the authors pointed out $7.38 \%$ of cases of ductal carcinoma in situ $(\mathrm{n}=9)$. There was an incidence of $12.29 \%(\mathrm{n}=15)$ for other types such as infiltrating ductal carcinoma, well-differentiated adenocarcinoma, invasive mucinous carcinoma, undifferentiated metaplastic carcinoma, and absence of carcinoma after neoadjuvant chemotherapy. These data partially corroborate the results of our study, especially when considering the high frequency of IDC; nevertheless, they differ regarding percentages of invasive lobular carcinoma and carcinoma in situ, which, in the first study, are higher.

According to Table 3, it can be observed that the expression of ER and PR was inversely proportional to the nuclear grade. Therefore, the highest expression of HR (ER and PR) was related to the lower nuclear grade. This inverse correlation proved to be statistically significant $(\mathrm{p}<0.01)$, similar to the findings of Dayal et al. ${ }^{20}$, according to which when ER expression was null, the incidence of nuclear grade 3 was higher than $50 \%$. Conversely, when the expression of ER was 3+, there was a higher incidence of nuclear grade 1 . In a similar study conducted in Asia ${ }^{21}$, ER positivity was observed in $70 \%$ of grade I carcinomas; in $48.2 \%$ of grade II; and in $3.5 \%$ of grade III ( $\mathrm{p}<0.001)$. Likewise, PR positivity was perceived in $70 \%$ of grade I carcinomas; in $36.14 \%$ of grade II; and in $1.75 \%$ of grade III ( $p<0.001)$, which corroborates our results. Thus, we can perceive that betterdifferentiated tumors (lower nuclear grade) are more likely to be ER and PR positive, in addition to having a relatively better prognosis, since it is known that the presence of HR (ER and $\mathrm{PR}$ ) in the tumor tissue is well correlated with the response to hormone therapy and chemotherapy ${ }^{22}$.

On the other hand, we observed that the increased expression of Ki-67 was related to a higher incidence of high nuclear grade, since we found a positive and statistically significant correlation. This shows that high cell proliferation, demonstrated in the overexpression of Ki-67, is mainly present in carcinomas of higher histologic grade, being a marker of tumor progression and worse prognosis ${ }^{23}$. Such a result is in line with the findings of Narbe et al. ${ }^{24}$, who also verified a significant positive correlation between Ki-67 and histologic grade $(\mathrm{p}<0.001)$, observing grade III tumors and Ki-67 mean value of $23.2 \%$.

Moreover, Table 3 illustrates that HER2, although not statistically significant $(p>0.211)$, presented the same trend as Ki-67 in relation to the histologic grade. A similar result was found by Arantes Júnior ${ }^{25}$, who did not observe a statistically significant correlation, although he pointed out that the overexpression of HER2 was related to high nuclear grade ( $\mathrm{p}$-value ranging from 0.113 to 0.451 ). Thus, we found that the overexpression of HER2 seems to be an independent marker of biological aggressiveness, since it has no statistical significance when related to different levels of nuclear grade. Its overexpression in breast cancer indicates decreased survival due to poor prognosis and low response to tamoxifen (hormone therapy) 22 .

Concerning tumor size, the mean size in patients with ER-positive tumors was $3.52 \mathrm{~cm}$ versus $3.73 \mathrm{~cm}$ in patients with ER-negative tumors, according to Table 4. Similarly, in patients with PR-positive tumors, the mean tumor size was 3.51 versus $3.72 \mathrm{~cm}$ in patients with PR-negative tumors; however, no significant correlation was established between tumor size and HR expression ( $p=0.714$ and $p=0.698$, respectively). A similar result was found by Dayal et al. ${ }^{20}$ and Ariga et al. ${ }^{26}$

It is known that lymph node status is important for determining breast cancer staging and treatment options. It is noteworthy that lymph node status consists of the most relevant factor in the prognosis of patients with breast cancer, since, as the number of positive axillary lymph nodes and the recurrence rate increase, the survival rate decreases. According to previous studies ${ }^{20,27,28}$, there is a statistically significant correlation between HER2 expression and lymph node involvement and 
vascular invasion, which has not been demonstrated for ER and PR. Nevertheless, this correlation was not found for any of these biomarkers in the present study.

\section{CONCLUSION}

Breast cancer is complex and heterogeneous, in addition to having a high prevalence in the female population. Hence, its correct classification is paramount for the best staging of the disease as well as for choosing the most appropriate therapeutic option. Therefore, immunohistochemical evaluation is key for the best diagnostic accuracy when associated with the tumor histopathological examination.

The present study aimed to evaluate the expression of ER and PR, the presence of HER2 oncogene, and proliferation antigen Ki-67, correlating them with the nuclear grade of the tumor. A higher prevalence of luminal A subtype was perceived, in addition to an inversely proportional relationship between the presence of HR and the nuclear grade of the tumor, with statistical relevance $(\mathrm{p}<0.01)$. Moreover, an important relationship was observed between the expression of the antigen Ki-67 and lower nuclear grade, i.e., with a lower differentiation grade and, consequently, worse prognosis.

Table 4. Distribution of the intensity of expression of hormone receptors according to tumor size.

\begin{tabular}{|c|c|c|c|}
\hline \multirow[b]{2}{*}{$\begin{array}{l}\text { Expression } \\
\text { of hormone } \\
\text { receptors }\end{array}$} & \multirow[b]{2}{*}{$\mathbf{N}$} & \multicolumn{2}{|c|}{ Tumor size } \\
\hline & & $\begin{array}{c}\text { Mean } \pm \\
\text { standard } \\
\text { deviation }\end{array}$ & $\begin{array}{l}\text { Pearson's } \\
\text { Correlation }\end{array}$ \\
\hline
\end{tabular}

Estrogen receptor

\begin{tabular}{|c|c|c|c|c|}
\hline Absent & 96 & $3.79 \pm 3.03$ & \multirow{4}{*}{-0.52} & \multirow{4}{*}{0.55} \\
\hline $1+$ & 27 & $3.87 \pm 2.68$ & & \\
\hline $2+$ & 32 & $3.55 \pm 2.20$ & & \\
\hline $3+$ & 120 & $3.47 \pm 3.01$ & & \\
\hline \multicolumn{5}{|c|}{ Progesterone receptor } \\
\hline Absent & 115 & $3.77 \pm 2.95$ & \multirow{4}{*}{-0.61} & \multirow{4}{*}{0.49} \\
\hline $1+$ & 28 & $3.60 \pm 1.96$ & & \\
\hline $2+$ & 17 & $4.91 \pm 3.58$ & & \\
\hline $3+$ & 115 & $3.34 \pm 2.95$ & & \\
\hline
\end{tabular}

Table 3. Correlation between intensity of expression of hormonal receptors, HER2 score, and Ki-67 product according to nuclear grade.

\begin{tabular}{|c|c|c|c|c|c|c|c|c|}
\hline \multirow{3}{*}{ Expression intensity } & \multicolumn{8}{|c|}{ Nuclear grade } \\
\hline & \multicolumn{2}{|c|}{1} & \multicolumn{2}{|c|}{2} & \multicolumn{2}{|c|}{3} & \multirow{2}{*}{$\begin{array}{c}\text { Mean } \pm \text { standard } \\
\text { deviation }\end{array}$} & \multirow{2}{*}{$\begin{array}{l}\text { Spearman's } \\
\text { Correlation } \\
\text { Coefficient }\end{array}$} \\
\hline & $\mathbf{N}$ & $\%$ & $\mathbf{N}$ & $\%$ & $\mathbf{N}$ & $\%$ & & \\
\hline
\end{tabular}

Estrogen receptor

\begin{tabular}{|c|c|c|c|c|c|c|c|c|}
\hline Absent & 0 & 0.0 & 41 & 54.7 & 34 & 45.3 & $2.45 \pm 0.50$ & \multirow{4}{*}{$-0.278 *$} \\
\hline $1+$ & 2 & 9.1 & 13 & 59.1 & 7 & 31.8 & $2.22 \pm 0.61$ & \\
\hline $2+$ & 0 & 0.0 & 20 & 83.3 & 4 & 16.7 & $2.16 \pm 0.38$ & \\
\hline $3+$ & 9 & 8.7 & 74 & 71.8 & 20 & 19.4 & $2.10 \pm 0.52$ & \\
\hline \multicolumn{9}{|c|}{ Progesterone receptor } \\
\hline Absent & 1 & 1.1 & 51 & 55.4 & 40 & 43.5 & $2.42 \pm 0.51$ & \multirow{4}{*}{$-0.312^{*}$} \\
\hline $1+$ & 2 & 9.1 & 15 & 68.2 & 5 & 22.7 & $2.13 \pm 0.56$ & \\
\hline $2+$ & 0 & 0.0 & 8 & 53.3 & 7 & 46.7 & $2.46 \pm 0.51$ & \\
\hline $3+$ & 8 & 8.4 & 74 & 77.9 & 13 & 13.7 & $2.05 \pm 0.46$ & \\
\hline \multicolumn{9}{|l|}{ HER2 Product } \\
\hline Absent & 4 & 4.7 & 56 & 65.9 & 25 & 29.4 & $2.24 \pm 0.53$ & \multirow{4}{*}{0.084} \\
\hline $1+$ & 6 & 7.9 & 56 & 73.7 & 14 & 18.4 & $2.10 \pm 0.50$ & \\
\hline $2+$ & 0 & 0.0 & 6 & 85.7 & 1 & 14.3 & $2.14 \pm 0.37$ & \\
\hline $3+$ & 2 & 3.5 & 30 & 52.6 & 25 & 43.9 & $2.40 \pm 0.56$ & \\
\hline \multicolumn{9}{|c|}{ Ki-67 product score } \\
\hline [0.0-25.0\%] & 10 & 9.1 & 84 & 76,4 & 16 & 14.5 & $2.05 \pm 0.48$ & \multirow{4}{*}{$0.367 *$} \\
\hline [25.0-50.0\%] & 1 & 2.2 & 30 & 65.2 & 15 & 32.6 & $2.30 \pm 0.51$ & \\
\hline$[50.1-75 \%]$ & 0 & 0.0 & 14 & 48.3 & 15 & 51.7 & $2.51 \pm 0.50$ & \\
\hline$>75.0 \%$ & 0 & 0.0 & 19 & 50.0 & 19 & 50.0 & $2.50 \pm 0.50$ & \\
\hline
\end{tabular}

*Statistically significant difference ( $p<0.01)$ according to Spearman's Correlation Coefficient. 
These results demonstrate the importance of tumor analysis performed according to immunohistochemistry and associated with histopathology. However, it is worth emphasizing that our research has limitations, especially due to the sample, and should be complemented with further studies addressing a larger number of patients.

\section{AUTHORS' CONTRIBUTION}

M.C.S.: wrote the original draft; I.J.M.R wrote the original draft. I.C.T.S.A.: wrote the original draft.

J.V.P.A.: wrote the original draft.

A.M.M.: wrote the original draft.

L.B.D.J.: supervised and wrote the original draft.

\section{REFERENCES}

1. Geyer FC, De Nigro MV. Tipos histológicos especiais de câncer de mama. Rev Onco\&. 2013;15:28-32.

2. Goldhirsch A, Winer EP, Coates AS, Gelber RD, PiccartGebhart M, Thürlimann B, et al. Personalizing the treatment of women with early breast cancer: highlights of the St Gallen International Expert Consensus on the Primary Therapy of Early Breast Cancer 2013. Ann Oncol. 2013;24(9):2206-23. https://doi.org/10.1093/annonc/mdt303

3. Viale G. The current state of breast cancer classification. Ann Oncol. 2012;23(Supl. 10):x207-10. https://doi.org/10.1093/ annonc/mds326

4. Pachnicki JPA, Czeczko NG, Tuon F, Cavalcanti TS, Malafaia AB, Tuleski AM. Avaliação imunoistoquímica dos receptores de estrogênio e progesterona no câncer de mama, pré e pósquimioterapia neoadjuvante. Rev Col Bras. 2012;39(2):86-92. http://dx.doi.org/10.1590/S0100-69912012000200002

5. Cintra JRD, Teixeira MTB, Diniz RW, Gonçalves Junior H, Florentino TM, Freitas GF, et al. Perfil imuno-histoquímico e variáveis clinicopatológicas no câncer de mama. Rev Assoc Med Bras. 2012;58(2):178-87. http://dx.doi.org/10.1590/S010442302012000200013

6. Becker RG, Galia CR, Morini S, Viana CR. Expressão imunohistoquímica das proteínas vegf e her-2 em biópsias de osteossarcoma. Acta Ortop Bras. 2013;21(4):233-83.

7. American Joint Committee on Cancer (AJCC). Cancer Staging Manual. $6^{a}$ ed. AJCC; 2002.

8. Lebeau A, Kriegsmann M, Burandt E, Sinn HP. [Invasive breast cancer: the current WHO classification]. Pathologe. 2014;35(1):7-17. https://doi.org/10.1007/s00292-013-1841-7

9. Pérez-Rodríguez G. Prevalence of breast cancer sub-types by immunohistochemistry in patients in the Regional General Hospital 72, Instituto Mexicano del Seguro Social. Cir Cir. 2015;83(3):193-8. https://doi.org/10.1016/j.circir.2015.05.003

10. Mendoza del Solar G, Echegaray A, Caso C. Perfil inmunohistoquímico del cáncer de mama en pacientes de un hospital general de Arequipa, Perú. Rev Med Hered. 2015;26(1):31-4.

11. Hammond MEH, Hayes DF, Dowsett M, Allred DC, Hagerty KL, Badve S, et al. American Society of Clinical Oncology/ College of American Pathologists guideline recommendations for immunohistochemical testing of estrogen and progesterone receptors in breast cancer. J Clin Oncol. 2010;28(16):2784-95. https://doi.org/10.1200/JCO.2009.25.6529
12. Cherbal F, Gaceb H, Mehemmai C, Saiah I, Bakour $\mathrm{R}$, Rouis AO, et al. Distribution of molecular breast cancer subtypes among Algerian women and correlation with clinical and tumor characteristics: a populationbased study. Breast Dis. 2015;35(2):95-102. https://doi. org/10.3233/BD-150398

13. Carvalho FM, Bacchi LM, Pincerato KM, Van de Rijn $\mathrm{M}$, Bacchi CE. Geographic differences in the distribution of molecular subtypes of breast cancer in Brazil. BMC Womens Health. 2014;14:102. https://doi.org/10.1186/14726874-14-102

14. Sánchez-Muñoz A, Román-Jobacho A, Pérez-Villa L, SánchezRovira P, Miramón J, Pérez D, et al. Male breast cancer: immunohistochemical subtypes and clinical outcome characterization. Oncology. 2012;83(4):228-33. https://doi. org/10.1159/000341537

15. Fourati A, Boussen H, El May MV, Goucha A, Dabbabi B, Gamoudi A, et al. Descriptive analysis of molecular subtypes in Tunisian breast cancer. Asia Pac J Clin Oncol. 2014;10(2):e6974. https://doi.org/10.1111/ajco.12034

16. Hagemann IS. Molecular Testing in Breast Cancer: A Guide to Current Practices. Arch Pathol Lab Med. 2016;140(8):815-24. https://doi.org/10.5858/arpa.2016-0051-RA

17. Meattini I, Bicchierai G, Saieva C, De Benedetto D, Desideri I, Becherini C, et al. Impact of molecular subtypes classification concordance between preoperative core needle biopsy and surgical specimen on early breast cancer management: Singleinstitution experience and review of published literature. Eur J Surg Oncol. 2017;43(4):642-8. https://doi.org/10.1016/j. ejso.2016.10.025

18. Caldarella A, Buzzoni C, Crocetti E, Bianchi S, Vezzosi $\mathrm{V}$, Apicella P, et al. Invasive breast cancer: a significant correlation between histological types and molecular subgroups. J Cancer Res Clin Oncol. 2013;139(4):617-23. https:// doi.org/10.1007/s00432-012-1365-1

19. Smaniotto ACR, Oliveira HR, Botogoski SR, Nalevaiko JZ, Costa L, Damião N. Perfil clínico, histológico e biológico de pacientes submetidos à biópsia do linfonodo sentinela por câncer de mama. Arq Med Hosp Fac Cienc Med Santa Casa São Paulo. 2013;58(3):121-6.

20. Dayal A, Shah JR, Kothari S, Patel SM. Correlation of Her-2/neu Status With Estrogen, Progesterone Receptors and Histologic Features in Breast Carcinoma. Ann Pathol Laboratory Medicine. 2016;3(5 Supl.):477-83. 
21. Azizun-Nisa, Bhurgri Y, Raza F, Kayani N. Comparison of ER, PR \& HER-2/neu (C-erb B 2) Reactivity Pattern with Histologic Grade, Tumor Size and Lymph Node Status in Breast Cancer. Asian Pac J Cancer Prev. 2008;9(4):553-6.

22. Siadati S, Sharbatdaran M, Nikbakhsh N, Ghaemian N. Correlation of ER, PR and HER-2/Neu with other Prognostic Factors in Infiltrating Ductal Carcinoma of Breast. Iran J Pathol. 2015;10(3):221-6.

23. Wang B, Wang X, Wang J, Xuan L, Wang Z, Wang X, et al. Expression of Ki67 and clinicopathological features in breast cancer. Zhonghua Zhong Liu Za Zhi. 2014;36(4):273-5.

24. Narbe U, Bendahl PO, Grabau D, Rydén L, Ingvar C, Fernö M. Invasive lobular carcinoma of the breast: long-term prognostic value of Ki67 and histological grade, alone and in combination with estrogen receptor. SpringerPlus. 2014;3:70. https://doi. org/10.1186/2193-1801-3-70
25. Arantes Júnior JC. Perfis Histopatológico e Imunohistoquímico do câncer de mama: Comparação entre lesões palpáveis e não-palpáveis [tese]. Botucatu: Universidade Estadual Paulista "Júlio de Mesquita Filho"; 2006.

26. Ariga R, Zarif A, Korasick J, Reddy V, Siziopikou K, Gattuso P. Correlation of Her-2/neu gene amplification with other prognostic and predictive factors in female breast carcinoma. Breast J. 2005;11(4):278-80. https://doi.org/10.1111/j.1075-122x.2005.21463.x

27. Tokatli F, Altaner S, Uzal C, Ture M, Kocak Z, Uygun K, et al. Association of HER-2 over expression with the number of involved axillary lymph nodes in human receptor positive breast cancer patients. Exp Oncol. 2005;27(2):145-9.

28. Abdollahi A, Sheikhbahaei S, Safinejad S, Jahanzad I. Correlation of ER, PR, HER- 2 and P53 Immunoreactions with Clinico-Pathological Features in Breast Cancer. Iran J Pathol. 2013;8(3):147-52. 